\title{
RESPONSE TO LAIDLAW-JOHNSON
}

\author{
PAUL F. JOHNSON \\ University of lllinois
}

It is always a risky business to attempt to say just what Plato's final pronouncement might be on one or another of the various doctrines that are presented throughout the course of the Dialogues. The same topic may be addressed from different angles at various points in the Corpus, and the contingencies of one discussion may require the emphasis of a particular point that is only just mentioned, or neglected altogether, in another. The difficulties are multiplied, of course, when the doctrine to be considered is as complicated and slippery as the question of human knowledge. We have just heard an attempt to say what Plato's theory of knowledge is. The various elements in this "Combined Theory" are brought together from various points in the Dialogues for the purpose of resolving some paradoxes that emerge in the Theaetetus. My comments here will be directed towards two separate but related issues. I begin with the question as to whether the Combined Theory as presented is consistent with what Plato has to say concerning knowledge and education at a point that I believe to be of some relevance to our reader's thesis, namely, Book VIl of the Republic, and propose then to examine whether the Theory is able to do the work its author intends for it.

The Combined Theory is centered around two claims, first, that we acquire knowledge of the forms through recollection by use of our senses, and second, that only with such knowledge are we able to know cognized external objects. In Book VII of the Republic, Socrates is discussing with Glaucon the sort of education that would be appropriate for the guardians of the state. If we take the first claim of the Combined Theory to mean that our approach to knowledge of the forms begins with perception, we must bear in mind a distinction that Socrates draws in his discussion with Glaucon between perceptions which "invite the intellect to reflection" and those which do not. (523b4). "Some reports of our perceptions," we read, "do not provoke thought...because the judgment of them by sensation seems adequate." An example of this sort of perception would be our consideration of the fingers of our own hand: we see the finger and observe forthwith that it is, indeed, a finger. The experiences that Socrates calls "provocatives," on the other hand, occur when "the perception no more manifests one thing than its contrary." Examples here include such things as bigness and smallness, hardness and softness and the like. When we look at a finger, to make the two examples clear, there is no doubt that it is a finger, but the same finger may appear large when compared to a child's, or small when compared to someone whose hand is 
larger than our own; the same finger appears hard when we use it to perforate the seal on some package, and soft when we bump it against some sharp object. There is no largeness or smallness to be seen in the finger itself, no hardness or softness. The specific instance of such provocatives that Socrates wants to consider is the contradictory pair, one/many. In this case, when we look at some object, as Glaucon is induced to say, "we see the same thing at once as one and as an indefinite plurality" (525a). This contradiction which arises from perception leads the mind on to the consideration of unity and plurality in themselves, and is the experiential basis for the study of arithmetic. Because this branch of study "compels the soul to employ pure thought with a view to truth itself" (526b), it is held to be a subject that must be included in the curriculum under which the prospective guardians of the state are to be trained.

We may fairly grant, at this point, that there is nothing in these passages which directly conflicts with the claim of the Combined Theory that knowledge of the forms begins with perception. The significance of this distinction between perceptions which are provocative of thought and those which are not will only be seen if we recall a few details of the manner in which our knowledge of the forms contributes to knowledge of external objects as this is elaborated under the terms of the Combined Theory. The machinery of knowledge seems to work something like this: We begin with perception and move upwards by a process of recollection to a knowledge of the forms. This knowledge of the forms is a necessary condition for such other cognitive functions as reflection and comparison, which latter functions permit the soul to grasp the ousia of a given object. l'll quote the specific passages from Ms. Laidlaw-Johnson's paper:

...prior knowledge (of forms) allows one to produce the additional mental activity of comparison to transform data into an external object. The mind, through its awareness of the ousia of the external object, combines this single datum of the object with other data of the same object into the cognition of the external object.... The perceiver's awareness of the ousia of the external object--that it is a complex of data transformed into an external object via the comparative use of the forms--transforms the possession of infallible perceptions into knowledge of the external object. (p. 160)

Knowledge of the forms, then, provides for the possibility of the mind's grasping ousia. Ousia, in turn, provides the ground upon which the diverse data of perception can be fused into a single, integral whole. This integrated fusion of the particulars of perception with the more abstract ousia gives us knowledge of the external object.

As I indicated a moment ago, I quite agree that our progress towards knowledge of the forms must begin with perception, but we must here take stock of the sort of perception from which this knowledge begins. Only 
those perceptions which manifest the peculiar form of contradiction adduced above are capable of initiating the mind's ascent towards knowledge of the forms. When we ask the further question of how such knowledge figures into our apprehension of the objects of sense, we must bear in mind the two types of perception that are available to the mind. We have, on the one hand, those perceptions of which the judgments of sensations are adequate on their own terms. On the other hand, we have the contradictory perceptions which we should not expect ever to relinquish their contradictory nature. Under the Combined Theory, we make use of our knowledge of the forms by returning to the data of perception, where they facilitate a process of synthesis and thereby give us knowledge of what had previously been nothing more than a collection of discrete perceptions. It's this last move that worries me. The clear thrust of the discussion in Book VII is that the prospective guardians must be encouraged to pursue the various studies that Socrates lists, arithmetic, geometry, astronomy and so forth, not solely for the sake of what utility they may have with regard to understanding the world, but rather, and more importantly, for the sake of leading the souls of these students towards a contemplation of the forms themselves. Socrates says at one point (talking of geometry), that "in fact the real object of the entire study is pure knowledge." This phrasing leaves open the possibility, of course, that there is some other sort of knowledge besides this "pure" sort, but he goes on to deny that the matter of sense perception can ever really be an object of learning. He says,

.if anyone tries to learn about the things of sense, whether gaping up or blinking down, I would never say that he really learns--for nothing of the kind admits of true knowledge--nor would I say that his soul looks up, but down, even though he study floating on his back on sea or land. (529b-c)

This claim must be weighed, of course, against the earlier claim which Socrates makes, that arithmetic, geometry, and so on, have an important practical application for the guardians, especially in connection with military planning. It seems quite clear, however, that Socrates is here denying that there is any real question of knowledge where the things of sense are concerned.

A further point is worth mentioning here, in connection with Ms. Laidlaw-Johnson's interpretation of the nature of the learning process. We read (p. 157) that "the doctrine of the Republic (Book VI) lis] compatible with the doctrine in Phaedo." This pertains to the doctrine that knowledge of the forms comes through a process of recollection, a doctrine presented in the Meno as well. Book VII, however, suggests that recollection is not perhaps the only such means of access to the forms. Socrates says there, concerning the subjects to be studied by the 
guardians, that "if these studies go far enough to bring out their community and kinship with one another, and to infer their affinities, then to busy ourselves with them contributes to our desired end, and the labor taken is not lost, but otherwise it is vain" $(531 \mathrm{c}-\mathrm{d})$. This passage does not explicitly confute the doctrine of recollection, of course. I mention it more for the sake of showing how difficult it is to establish any one doctrine concerning knowledge of the forms as the one correct version.

I turn now to a consideration of Ms. Laidlaw-Johnson's attempt to resolve the paradoxes which appear in the Theaetetus. For the sake of brevity, I'll limit my remarks to the first of the paradoxes, which arises from the conflict between two implicit claims made by Socrates, that, on the one hand, knowledge can be acquired through teaching, and on the other, that knowledge can only be had through direct perception. It occurs to me that the question of knowledge as it bears on the fact of a given case of robbery needn't involve us in a discussion of how we might achieve knowledge of the forms. I say this for two reasons. First, if we take seriously the claim in Book VII of the Republic that we can never really speak of our having knowledge of the things of sense, but that our "judgments of sense" are somehow adequate on their own terms, then it seems plausible to suggest that the best we can hope for in establishing the facts of the case is that the jurors be convinced one way or another. If they are "judging without knowledge," it is not simply because of the constraints of time in the courtroom that they fail to attain such knowledge, but rather because knowledge of perceptual events is not to be expected in any case. This leaves us, of course, with the difficult assertion that the facts of the case can be known to an eyewitness. What can be "known" to the eyewitness should be appraised on the basis of whatever standards are appropriate to our "judgments of sense," a standard which it is not clear, given the claims from Book VII, need involve us in the question of the relation of the forms to perception.

Second, in resolving the paradox by restating the two apparently conflicting claims as 1) knowledge of forms is acquired partially through teaching and 2) the acquisition of all knowledge requires perception, we might expect that, absent the constraints of time in the courtroom, our jurors might indeed be brought to knowledge of the events in question, in which case they could "judge with knowledge" instead of without it. But in the very nature of the case where we are speaking of events to which we were not an eyewitness, it seems unlikely that we shouid ever attain the sort of awareness we have of things before our eyes. Again, the best we can hope for is a relatively high assurance of what actually happened. It would seem a more plausible approach to resolving the apparent paradox to point out that Socrates has simply equivocated on the crucial term "knowledge," confusing the sense in which we have knowledge of the forms ("pure knowledge"), knowledge of sensory objects (involving the rather different "judgments of sense"), and the knowledge we might reasonably 
expect to have of a past event (a different problem altogether). One's preference for this approach would depend, of course, upon the extent to which one cares to incorporate the claims of Book VII into one's account of knowledge. My point in suggesting such an alternative is intended not so much to refute our reader's attempt to resolve the paradox by the methods she has chosen, but only to show that the further claim, that this approach can give us a completely consistent and final statement of Plato's theory of knowledge, is problematic at best.

One further remark by way of summing up. At the very outset of her paper, Ms. Laidlaw-Johnson raises the question, "Just what is Plato's project" in the Theaetetus? Her response to that question seems to be that he is working his way towards some concise formulation of a theory of knowledge, a theory which emerges only when we look to his various pronouncements in other Dialogues. The task she has taken upon herself is to try to bring these dispersed elements together into a definitive whole. Though I am skeptical of her results, I must nonetheless admire the elegance and force of her argument. For my part, I wonder whether such a definitive theory could ever be elaborated, given both the complexity of the issue and the wide range of comments that we find throughout the Corpus. We find certain passages, as 1 have tried to point out in the foregoing comments, that just cannot be completely harmonized with one another, and whatever theory we might hope to establish as Plato's final thought on the matter will always require us to pick and choose which passages are to be given preference, and which are to be excluded. As I read the Theaetelus, what Plato seems to be telling us is just that no such complete and concise theory of knowledge should be expected, in spite of the fact that we claim to have knowledge of this or that, that we use the word "knowledge" without any reservations concerning our correct use of the term. At one point in the discussion, Socrates says to Theaetetus that their whole discussion was blemished by a "vicious taint" (196e2). "Times out of number," he continues, "we have said 'we know;" 'we do not know; 'we have knowledge, 'we have no knowledge,' as if we could understand each other while we still know nothing about knowledge." The point of the Dialogue, it seems to me, is that we simply cannot say what knowledge is: hence the refutations which follow in quick order as the discussion unfolds. Which is not to say that the question, "What is knowledge?" is useless or futile. The Dialogue itself is a demonstration that knowledge consists in its pursuit, and that we have made an important gain even if we achieve no more than a recognition that we remain ignorant on the central point of our discussion. It is only by engaging in the exercise of such discussions that we attain to such a realization, and thereby take upon ourselves the modesty which comes of knowing that we do not know. To instill in us the "good sense not to fancy we know what we do not," is all that Socrates claims his art is capable of achieving. We should perhaps take him at his wond. 